\title{
The role of valence and frequency in the emotional Stroop task
}

\author{
Todd A. Kahan and Charles D. Hely \\ Bates College, Lewiston, Maine
}

\begin{abstract}
People are generally slower to name the color of emotion-laden words than they are to name that of emotionally neutral words. However, an analysis of this emotional Stroop effect (Larsen, Mercer, \& Balota, 2006) indicates that the emotion-laden words used are sometimes longer, have lower frequencies, and have smaller orthographic neighborhoods than the emotionally neutral words. This difference in word characteristics raises the possibility that the emotional Stroop effect is partly caused by lexical rather than by emotional aspects of the stimuli-a conclusion supported by the finding that reaction times to name the color of low-frequency words are longer than those for high-frequency words (Burt, 2002). To examine the relative contributions of valence and frequency in color naming, we had 64 participants complete an experiment in which each of these variables was manipulated in a $3 \times 2$ factorial design; length, orthographic neighborhood density, and arousal were balanced. The data indicate that valence and word frequency interact in contributing to the emotional Stroop effect.
\end{abstract}

In the color-word Stroop task, participants are shown color names in a colored font, and they must respond to the color of the font while ignoring the words themselves (Stroop, 1935). Results generally indicate that responses to colors that are incongruent with the word (e.g., the word red in the color green) are slower and less accurate than responses to colors that are congruent with the word (e.g., the word red in the color red) - that is, a color-word Stroop effect. This task has been used to examine the automaticity of word reading (Neely \& Kahan, 2001) as well as the nature of selective attention (MacLeod, 1991), and it has been studied extensively since Stroop's original article in 1935. In the "emotional Stroop" variant of this procedure, participants are asked to respond to the color of emotionladen words that can be positive (e.g., beauty), negative (e.g., death), or emotionally neutral (e.g., truck), rather than words that are congruent or incongruent with the color. It is generally found that participants take longer to respond to the color of emotion-laden words than to that of emotionally neutral words - that is, an "emotional Stroop effect"and this task has been used to study the cognitive processes involved in ignoring emotional information as well as how these processes vary across clinical and nonclinical populations (Williams, Mathews, \& MacLeod, 1996).

However, Algom, Chajut, and Lev (2004) pointed out that the emotional Stroop task differs in important ways from the color-word Stroop task, and Larsen, Mercer, and Balota (2006) raised the possibility that these methodological differences might compromise the theoretical interpretations that have been drawn. Specifically, the words to be ignored in the emotion-laden (e.g., death) and emotionally neutral (e.g., truck) conditions of the emotional Stroop task differ, whereas the words used in the congruent (e.g., red written in the color red) and incongruent (e.g., red written in the color blue) conditions of the color-word Stroop task are the same. As such, if lexical differences exist between the emotion-laden and emotionally neutral words, then any difference in reaction times (RTs) might reflect, in part, this lexical difference rather than differences in word valence (Larsen et al., 2006). In an analysis of 1,033 words used in 32 empirical investigations of the emotional Stroop effect, Larsen et al. found that the emotion-laden words used were often longer in length and lower in frequency of occurrence and had less dense orthographic neighborhoods ${ }^{1}$ than did the emotionally neutral control words. These lexical differences are critical, because Burt (2002, Experiment 4) has shown that participants take longer to name the color of low-frequency (LF) words than of high-frequency (HF) words, which reinforces the possibility that the differences observed in experiments using the emotional Stroop task may be partly caused by frequency.

However, knowing that frequency and valence have sometimes been confounded does not diminish the fact that the emotional Stroop effect has also been obtained in studies in which word frequency was either carefully equated (e.g., McKenna \& Sharma, 1995; Sutton \& Altarriba, 2008; Williams \& Nulty, 1986) or statistically controlled (e.g., Wentura, Rothermund, \& Bak, 2000). Therefore, the emotional Stroop effect cannot be entirely caused by word frequency. Additionally, knowing that frequency and valence have sometimes been confounded does not elucidate how these factors may independently or jointly affect color naming RTs. In fact, if Burt's (2002)

T. A. Kahan, tkahan@bates.edu 
LF words differed from her HF words in valence, it is possible that the frequency effect she reported in a colornaming experiment was partially caused by valence. To examine this possibility, we checked Burt's items against the Affective Norms for English Words (ANEW; Bradley \& Lang, 1999), which contains valence ratings of 1,034 words on a scale from 1 (objectionable) to 9 (pleasant). Of the 80 words appearing in Burt's Experiment 4, norms were only available for 16 items (10 HF and $6 \mathrm{LF})$; yet, even though there should not have been any systematic valence differences among these words, we found that her HF words were significantly more positive $(M=6.8)$ than her LF words $(M=4.6)[t(14)=3.4, p<.01]$, raising the possibility that the slowdown to LF words was partially (or entirely) caused by valence. To be clear, we are not claiming that valence was certainly the critical factor in Burt's Experiment 4; instead, we wish to point out that it is equally difficult to interpret frequency effects (or any effect in which different words appear in the different experimental conditions) when items are not balanced on other potentially important factors - in this case, valence.

To further assess the role of valence and frequency in word recognition, Estes and Adelman (2008) examined lexical decision and word-naming latencies ${ }^{2}$ for 1,011 words taken from the ANEW norms (Bradley \& Lang, 1999). The RT data they examined were taken from the English Lexicon Project (Balota et al., 2007), an online database containing RT data to 40,481 words collected from hundreds of participants. Before describing the results of their analysis, however, one must note that lexical decision and word-naming tasks involve attending torather than ignoring - words. Because of this, it is unclear whether the results observed will generalize to colornaming experiments. However, notwithstanding task differences, Estes and Adelman found that valence made an independent contribution to lexical decision and wordnaming latencies (negative words were responded to more slowly than positive words) that could not be ascribed to other lexical factors (e.g., length, frequency, orthographic neighborhood density).

If color-naming data perfectly mirror lexical decision and word-naming performance, then this same pattern should be found in the emotional Stroop task; both valence and frequency should make independent contributions to RTs. However, although some have reported that color naming, lexical decision, and word naming yield analogous valence effects (e.g., Algom et al., 2004), others have reported that the valence effects obtained using color naming disappear in lexical decision (MacKay et al., 2004). Furthermore, in those studies that do report analogous results across tasks, frequency was never manipulated, so it remains unclear whether valence and frequency will independently affect RTs in the emotional Stroop task or whether the two factors will interact. The present experiment will examine this possibility. Lastly, there are inconsistencies reported in the lexical decision literature that complicate matters further, with some researchers finding slowed responses to negative as compared with emotionally neutral words (e.g., Algom et al., 2004; Estes \& Adelman, 2008), others finding speeded responses (e.g.,
Kanske \& Kotz, 2007; Nakic, Smith, Busis, Vythilingam, \& Blair, 2006), and still others finding no valence differences (MacKay et al., 2004).

As Larsen et al. (2006) made clear, the emotional Stroop effect could partly reflect word frequency. The present experiment is the first to manipulate word frequency within the emotional Stroop task. Although some researchers have examined the effects of valence and word frequency in tasks involving attended words (e.g., lexical decision and word naming), nobody has examined this in a task involving ignored words. To do this, we had 64 participants complete a color-naming task in which valence and frequency were manipulated in a $3 \times 2$ factorial design; length, orthographic neighborhood, and arousal were balanced. Because most studies report larger effects for negative than for positive emotion-laden words (see, e.g., McKenna \& Sharma, 1995; Pratto \& John, 1991), we did not expect positive words to behave much differently than emotionally neutral words.

\section{METHOD}

\section{Participants}

Sixty-four introductory psychology students from Bates College participated for extra credit.

\section{Materials}

Sixty-six words were used; there were 11 words in each of the six experimental conditions created by crossing three levels of valence (positive, emotionally neutral, and negative) with two levels of frequency (HF and LF). All of the words that were used appeared in both the ANEW norms (Bradley \& Lang, 1999) - so that valence and arousal levels could be determined-and the English Lexicon Project (Balota et al., 2007) - so that length, word frequency, and orthographic neighborhood density could be determined. Words selected for the LF condition had Kučera and Francis (1967) frequency values no greater than 10 , whereas words selected for the HF condition had values no less than 50 . Words chosen for the negative valence condition had Bradley and Lang ratings no greater than 3.5, whereas words chosen for the positive condition had ratings no less than 6.5 ; words in the emotionally neutral condition had valence ratings between 3.5 and 6.5. The items were balanced on arousal, length, and orthographic neighborhood density; when separate $3 \times 2$ ANOVAs were performed treating each of these dimensions as the dependent variable, none of the effects approached significance (all $F_{\mathrm{S}}<1$ ). However, when Kučera and Francis frequency was treated as the dependent variable in a $3 \times 2$ ANOVA, there was a significant main effect of frequency $[F(1,60)=36.0, p<.01$; $\mathrm{HF}$ mean $=143.5$; LF mean $=5.1]$; none of the other effects approached significance. Likewise, when log HAL frequency norms (Lund \& Burgess, 1996) were used as the dependent variable, there was again a significant main effect of frequency $[F(1,60)=116.37$, $p<.01 ;$ HF mean $=10.6$; LF mean $=8.0]$; none of the other effects approached significance. Finally, when valence was treated as the dependent variable, there was a significant main effect of valence $[F(2,60)=370.45, p<.01$; positive mean $=7.2$; emotionally neutral mean $=5.5$; negative mean $=2.5$; Tukey's $\mathrm{CD}=.42]$; again, none of the other effects approached significance. A complete list of materials is provided in the Appendix, and descriptive statistics for these materials are shown in Table 1.

\section{Apparatus and Procedure}

Stimulus presentation and response timing were controlled using E-Prime version 1.2 software (Schneider, Eschman, \& Zuccolotto, 2002a, 2002b). Participants were seated in front of a computer, and, following a $250-\mathrm{msec}$ central white fixation $\left({ }^{*}\right)$, a word appeared in 
Table 1

Means and Standard Deviations of Arousal Ratings, Word Length, Orthographic Neighborhood Density, Bradley and Lang (1999) Valence, Kučera and Francis (1967) Frequency, and Log HAL Frequency for the Items Used, As a Function of Condition Type

\begin{tabular}{|c|c|c|c|c|c|c|c|c|c|c|c|c|}
\hline & \multicolumn{6}{|c|}{ Low Frequency } & \multicolumn{6}{|c|}{ High Frequency } \\
\hline & \multirow{2}{*}{\multicolumn{4}{|c|}{$\begin{array}{c}\text { Emotionally } \\
\text { Neutral }\end{array}$}} & \multirow{2}{*}{\multicolumn{2}{|c|}{ Positive }} & \multirow{2}{*}{\multicolumn{4}{|c|}{$\begin{array}{c}\text { Emotionally } \\
\text { Neutral }\end{array}$}} & \multirow{2}{*}{\multicolumn{2}{|c|}{ Positive }} \\
\hline & & & & & & & & & & & & \\
\hline & $M$ & $S D$ & $M$ & $S D$ & $M$ & $S D$ & $M$ & $S D$ & $M$ & $S D$ & $M$ & $S D$ \\
\hline Arousal & 5.1 & .7 & 5.0 & .8 & 5.2 & .7 & 5.3 & .6 & 5.0 & .6 & 5.0 & .5 \\
\hline Word length & 5.0 & 1.5 & 5.0 & 1.5 & 5.0 & 1.5 & 5.0 & 1.5 & 5.0 & 1.5 & 5.0 & 1.5 \\
\hline Orthographic neighborhood & 7.4 & 7.0 & 7.6 & 7.5 & 4.0 & 3.8 & 6.3 & 7.9 & 5.8 & 5.3 & 6.2 & 6.1 \\
\hline Bradley \& Lang valence & 2.6 & .6 & 5.4 & .7 & 7.2 & .4 & 2.4 & .6 & 5.5 & .5 & 7.3 & .6 \\
\hline Kučera \& Francis frequency & 4.3 & 3.4 & 6.1 & 3.2 & 5.8 & 2.4 & 131.2 & 73.2 & 110.6 & 60.2 & 188.6 & 209.0 \\
\hline Log HAL frequency & 8.2 & 1.0 & 7.7 & 1.0 & 8.1 & 1.3 & 10.5 & 0.6 & 10.4 & 0.9 & 10.9 & 1.0 \\
\hline
\end{tabular}

red, blue, yellow, or green; the background was black. This word remained visible until the participant named its color into a microphone. Between trials, there was a 2,500-msec blank interval.

Participants completed three blocks of trials. During a 12-item practice block, repeating Xs of 4 to 6 characters appeared instead of the experimental words. Following this presentation, participants completed two blocks of 66 trials. Each of the 66 words appeared once in each block, and the order of word presentation - as well as the color assigned to each word - was determined randomly on a trial-by-trial basis

\section{RESULTS}

Participants' geometric means of RT for correct responses $^{3}$ in each condition were submitted to a $3 \times 2$ repeated measures ANOVA. Arithmetic means of these geometric means are displayed in Figure 1. There was a main effect of valence $[F(2,126)=3.77, p<.05]$, a main effect of frequency $[F(1,63)=5.89, p<.05]$, and, most important, an interaction between the two $[F(2,126)=$ $3.16, p<.05]$. Two one-way ANOVAs were computed to help explain the interaction. A one-way ANOVA on RTs in the LF conditions was significant $[F(2,126)=6.62, p<$ .05 ; Tukey's $C D=10.79]$, whereas a one-way ANOVA on RTs in the HF conditions was not $[F(2,126)=0.023, p>$ $.05]$. LF negative emotion-laden words were responded to more slowly than those in the other conditions. Accuracy data were uniformly high (ranging from $98 \%$ to $98.5 \%$ across conditions) and yielded no significant differences.

\section{DISCUSSION}

These data demonstrate that Larsen et al. (2006) were correct in speculating that word frequency plays a role in the emotional Stroop effect. However, these data also make it clear that frequency — which has been confounded in some (but not all) studies - does not, by itself, explain the entire effect. Frequency and valence interact in affecting color-naming RTs. The reason why LF negative emotion words are responded to more slowly remains unclear, and will require further testing. What is clear is that (1) researchers who examine the emotional Stroop effect should not ignore word frequency and (2) they might choose to use LF words (since HF words did not show the effect in this experiment ${ }^{4}$ ), and the frequency effect reported by
Burt (2002) was replicated in the present experiment only when negative words were used.

\section{Theoretical Implications}

Both the frequency and valence of an ignored word are important factors that together affect color-naming RTs. The emotional Stroop effect varied with word frequency, and the frequency effect reported by Burt (2002) varied with word valence. Any complete explanation of either of these effects will need to explain why valence and frequency interact.

With regard to the emotional Stroop effect, one common explanation has been that threat words capture attention and are obligatorily processed, even though participants are asked to ignore these stimuli (i.e., there is an "attentional bias" toward these words) (see Williams et al., 1996, for a discussion of how this might arise in a connectionist model similar to that proposed by Cohen, Dunbar, $\&$ McClelland, 1990). However, if this were the case, it is unclear why the emotional Stroop effect was replicated only for LF negative words when these words would have weaker pathway strengths in a connectionist framework than would HF negative words.

Another explanation for the emotional Stroop effect is based on the notion that negative words trigger an automatic defense mechanism that interferes with concurrent

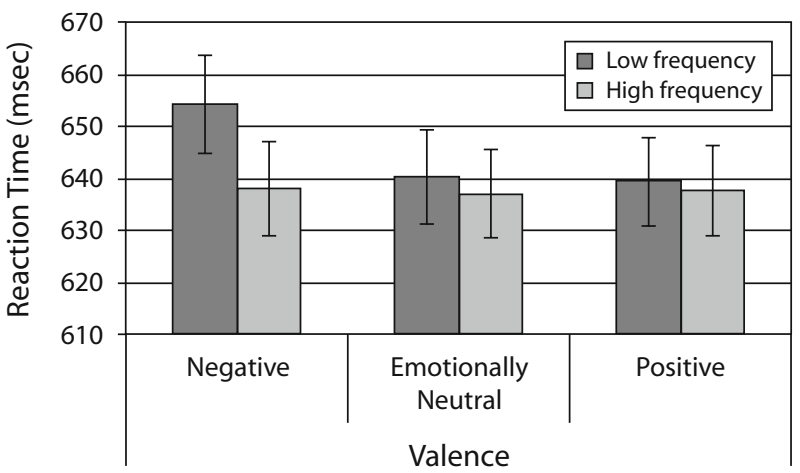

Figure 1. Mean reaction times, along with standard errors, to respond to the color of negative, emotionally neutral, or positive words that were either high or low in frequency of occurrence within the English language. 
cognitive processes (see, e.g., Algom et al., 2004; Pratto \& John, 1991). One nice feature of this explanation is that it easily accounts for lexical decision and wordnaming experiments that also show slowed responses to negative words, as compared with emotionally neutral or positive words (e.g., Algom et al., 2004; Estes \& Adelman, 2008); color naming should not be uniquely slowed by negative words. However, this explanation does not posit a special role for LF negative words and therefore cannot explain why valence and frequency interact in this experiment.

In terms of the frequency effect, Burt (2002) argued for a capacity-based model of color naming in which RTs are slowed when resources are allocated elsewhere. According to this explanation, both the word and color are processed in parallel, and color-naming responses are slower for LF words than for HF words, because more resources are devoted to processing LF than HF words, leaving fewer resources available for processing the color. However, on the basis of this explanation, emotionally neutral and positive emotion words should also exhibit a word frequency effect of equal magnitude. As such, the present data pose problems for existing theories of both the emotional Stroop effect and the word frequency effect in color naming.

\section{Conclusions}

Recent research has examined the relative contributions of valence and frequency in tasks in which participants attend to words (lexical decision and word naming). The present experiment examined the relative contributions of these factors in a task in which participants ignored words. Our data indicate that both valence and word frequency affect color-naming RTs and that these factors interact-a result that poses problems for extant theories.

We close with a point that was raised by Larsen et al. (2006). Researchers who compare the magnitude of the emotional Stroop effect across participants are not immune to frequency effects simply because both groups responded to the same set of unbalanced words; if the groups differ in their reading abilities, then differences in the emotional Stroop effect might reflect differences in how the two groups process frequency rather than valence. The emotional Stroop task is a very useful tool for examining theoretical and clinical questions, but we urge researchers to use caution when creating the experimental stimuli, matching on all variables that might affect the experimental outcome (e.g., balancing frequency), and this word of caution should similarly be followed by word recognition researchers who use lexical decision or word naming to examine frequency or other item-based effects (e.g., balancing valence).

\section{AUTHOR NOTE}

This work was generously supported by a Charles F. and Evelyn M. Phillips Faculty Fellowship from Bates College that was awarded to T.A.K. We are grateful to Zach Estes, Kathy Mathis, and Tina Sutton for their very helpful suggestions on this work. Correspondence should be addressed to T. A. Kahan, Department of Psychology, Bates College, Lewiston, ME 04240 (e-mail: tkahan@bates.edu).

\section{REFERENCES}

Algom, D., Chajut, E., \& Lev, S. (2004). A rational look at the emotional Stroop phenomenon: A generic slowdown, not a Stroop effect. Journal of Experimental Psychology: General, 133, 323-338.

Balota, D. A., Yap, M. J., Cortese, M. J., Hutchison, K. A., KessLer, B., LofTis, B., ET AL. (2007). The English Lexicon Project. Behavior Research Methods, 39, 445-459.

Bradley, M. M., \& Lang, P. J. (1999). Affective norms for English words (ANEW): Stimuli, instruction manual and affective ratings (Tech. Rep. No. C-1). Gainesville: University of Florida, Center for Research in Psychophysiology.

BURT, J. S. (2002). Why do non-color words interfere with color naming? Journal of Experimental Psychology: Human Perception \& Performance, 28, 1019-1038.

Cohen, J. D., Dunbar, K., \& McClelland, J. L. (1990). On the control of automatic processes: A parallel distributed processing account of the Stroop effect. Psychological Review, 97, 332-361.

Estes, Z., \& Adelman, J. S. (2008). Automatic vigilance for negative words in lexical decision and naming: Comment on Larsen, Mercer, and Balota (2006). Emotion, 8, 441-444.

KansKe, P., \& Kotz, S. A. (2007). Concreteness in emotional words: ERP evidence from a hemifield study. Brain Research, 1148, 138-148.

KuČERA, H., \& Francis, W. N. (1967). Computational analysis of present-day American English. Providence, RI: Brown University Press.

Larsen, R. J., Mercer, K. A., \& Balota, D. A. (2006). Lexical characteristics of words used in emotional Stroop experiments. Emotion, 6, 62-72.

Lund, K., \& Burgess, C. (1996). Producing high-dimensional semantic spaces from lexical co-occurrence. Behavior Research Methods, Instruments, \& Computers, 28, 203-208.

MacKay, D. G., Shafto, M., TaYlor, J. K., Marian, D. E., Abrams, L., \& DYER, J. R. (2004). Relations between emotion, memory, and attention: Evidence from taboo Stroop, lexical decision, and immediate memory tasks. Memory \& Cognition, 32, 474-488.

MacLeod, C. M. (1991). Half a century of research on the Stroop effect: An integrative review. Psychological Bulletin, 109, 163-203.

McKenna, F. P., \& Sharma, D. (1995). Intrusive cognitions: An investigation of the emotional Stroop task. Journal of Experimental Psychology: Learning, Memory, \& Cognition, 21, 1595-1607.

Nakic, M., Smith, B. W., Busis, S., Vythilingam, M., \& Blair, R. J. R. (2006). The impact of affect and frequency on lexical decision: The role of the amygdala and inferior frontal cortex. NeuroImage, $\mathbf{3 1}$, 1752-1761

NeELY, J. H., \& Kahan, T. A. (2001). Is semantic activation automatic? A critical re-evaluation. In H. L. Roediger III, J. S. Nairne, I. Neath, \& A. M. Surprenant (Eds.), The nature of remembering: Essays in honor of Robert G. Crowder (pp. 69-93). Washington, DC: American Psychological Association.

Pratto, F., \& John, O. P. (1991). Automatic vigilance: The attentiongrabbing power of negative social information. Journal of Personality \& Social Psychology, 61, 380-391.

Richards, A., French, C. C., Johnson, W., Naparstek, J., \& WilLIAMS, J. (1992). Effects of mood manipulation and anxiety on performance of an emotional Stroop task. British Journal of Psychology, 83, 479-491.

Schneider, W., Eschman, A., \& Zuccolotto, A. (2002a). E-Prime reference guide. Pittsburgh: Psychology Software Tools Inc.

Schneider, W., Eschman, A., \& Zuccolotto, A. (2002b). E-Prime user's guide. Pittsburgh: Psychology Software Tools Inc.

Sharma, D., \& McKenna, F. P. (2001). The role of time pressure on the emotional Stroop task. British Journal of Psychology, 92, 471-481.

Stroop, J. R. (1935). Studies of interference in serial verbal reactions. Journal of Experimental Psychology, 18, 643-662.

Sutton, T. M., \& Altarriba, J. (2008). Emotion words in the mental lexicon: A new look at the emotional Stroop effect. The Mental Lexicon, 3, 29-46.

Wentura, D., Rothermund, K., \& BaK, P. (2000). Automatic vigilance: The attention-grabbing power of approach- and avoidancerelated social information. Journal of Personality \& Social Psychology, 78, 1024-1037.

Williams, J. M. G., Mathews, A., \& MacLeod, C. [M.] (1996). The 
emotional Stroop task and psychopathology. Psychological Bulletin, 120, 3-24.

Williams, J. M. G., \& Nulty, D. D. (1986). Construct accessibility, depression and the emotional Stroop task: Transient mood or stable structure? Personality \& Individual Differences, 7, 485-491.

\section{NOTES}

1. Orthographic neighborhood density refers to the number of words that can be created from a word by changing one letter, while keeping the other letters unchanged and in the same positions. For example, the word desk has three orthographic neighbors: disk, deck, and dusk.

2. In the lexical decision task, participants decide whether a string of letters is, or is not, a properly spelled word by pressing one of two response keys. In word-naming experiments, participants pronounce words aloud as quickly and as accurately as possible.

3. The very first trial in Block 2 had unusually long RTs and was dropped; this affected all conditions equally because the items were presented in a completely random order.

4. We do not wish to claim that the emotional Stroop effect cannot be found under any circumstances with HF words. It remains possible that the emotional Stroop effect might emerge for HF words if the effect were strengthened by using a shorter interstimulus interval (see Sharma \& McKenna, 2001) or a blocked rather than a mixed presentation of negative words (see Richards, French, Johnson, Naparstek, \& Williams, 1992). The point we wish to make is that valence and frequency have an interactive relationship in which the emotional Stroop effect is larger for LF than for HF words.

APPENDIX

\begin{tabular}{|c|c|c|c|c|c|}
\hline Word & Valence & $\begin{array}{c}\text { Kučera-Francis } \\
\text { Frequency }\end{array}$ & Word & Valence & $\begin{array}{c}\text { Kučera-Francis } \\
\text { Frequency }\end{array}$ \\
\hline alone & negative & high & coin & emotionally neutral & low \\
\hline broken & negative & high & cork & emotionally neutral & low \\
\hline crisis & negative & high & doll & emotionally neutral & low \\
\hline dead & negative & high & hammer & emotionally neutral & low \\
\hline death & negative & high & owl & emotionally neutral & low \\
\hline failure & negative & high & pungent & emotionally neutral & low \\
\hline hell & negative & high & scissors & emotionally neutral & low \\
\hline lie & negative & high & swamp & emotionally neutral & low \\
\hline lost & negative & high & tease & emotionally neutral & low \\
\hline pressure & negative & high & vanity & emotionally neutral & low \\
\hline sick & negative & high & vest & emotionally neutral & low \\
\hline dump & negative & low & art & positive & high \\
\hline foul & negative & low & beauty & positive & high \\
\hline loser & negative & low & dream & positive & high \\
\hline maggot & negative & low & free & positive & high \\
\hline massacre & negative & low & freedom & positive & high \\
\hline poison & negative & low & nature & positive & high \\
\hline rat & negative & low & nice & positive & high \\
\hline scar & negative & low & progress & positive & high \\
\hline torture & negative & low & soft & positive & high \\
\hline trash & negative & low & wish & positive & high \\
\hline wasp & negative & low & world & positive & high \\
\hline body & emotionally neutral & high & cheer & positive & low \\
\hline chance & emotionally neutral & high & circus & positive & low \\
\hline coast & emotionally neutral & high & cuisine & positive & low \\
\hline hit & emotionally neutral & high & cute & positive & low \\
\hline hospital & emotionally neutral & high & humane & positive & low \\
\hline manner & emotionally neutral & high & puppy & positive & low \\
\hline news & emotionally neutral & high & thankful & positive & low \\
\hline patient & emotionally neutral & high & toy & positive & low \\
\hline ship & emotionally neutral & high & tune & positive & low \\
\hline truck & emotionally neutral & high & wink & positive & low \\
\hline wine & emotionally neutral & high & zest & positive & low \\
\hline
\end{tabular}

(Manuscript received December 30, 2007; revision accepted for publication May 7, 2008.) 